CORRECTION

\title{
Correction: microRNA-let-7e in serum-derived exosomes inhibits the metastasis of non-small-cell lung cancer in a SUV39H2/LSD1/CDH1-dependent manner
}

Shufeng Xu, Lei Zheng, Liying Kang, Hongmei Xu and Liming Gao (D)

(c) The Author(s), under exclusive licence to Springer Nature America, Inc. 2021

Cancer Gene Therapy (2022) 29:1071-1073; https://doi.org/10.1038/s41417-021-00402-9

Correction to: Cancer Gene Therapy https://doi.org/10.1038/ s41417-020-00216-1, published online 09 December 2020

1. Error: in the records of PCR experiment and WB experiment results in the clinical baseline data, there was an error in the correlation analysis results due to the lack of statistics during the recording. I traced all the original data and reanalyzed the correlation analysis results (Figs. 3D, 4E, K and 5C) 2. Causes: problems in the storage and statistics of clinical data records in this study. 3. Result: some data are lost (later found), and the overall result trend is correct. Therefore, it is requested to replace the results after reanalysis.

The original article has been corrected. 
A

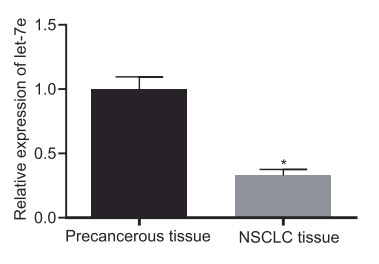

D

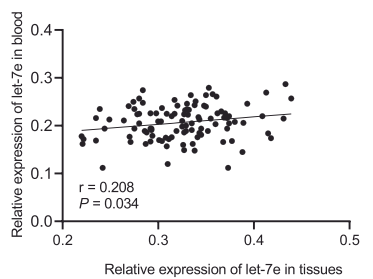

H

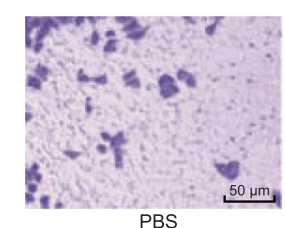

I

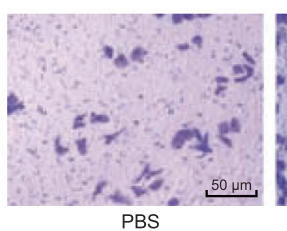

B

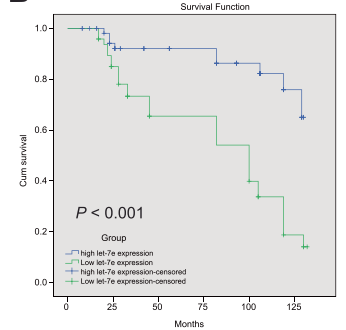

E

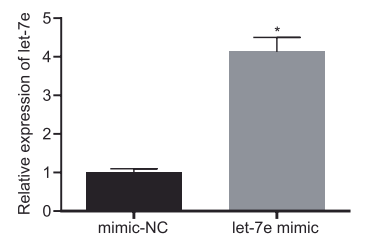

C

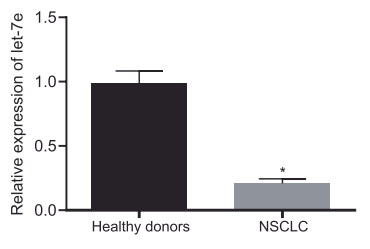

$\mathbf{F}$

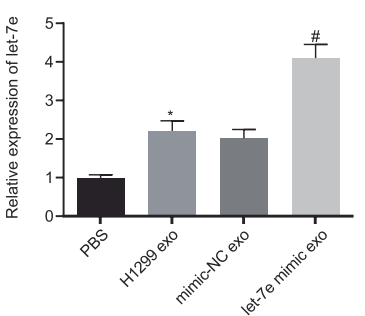

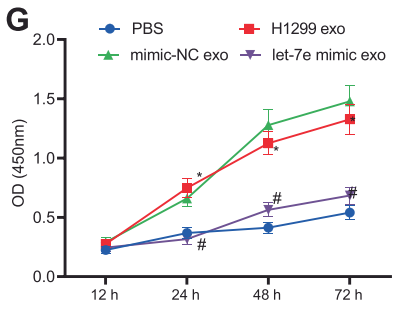
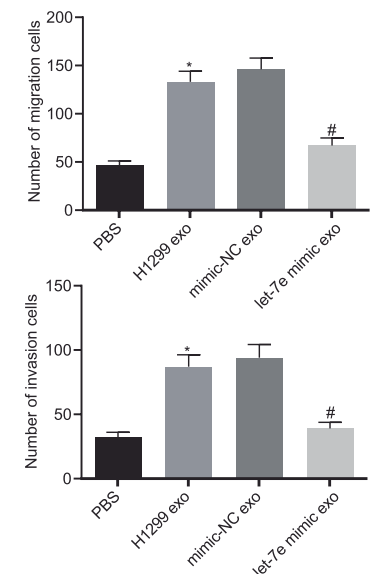

Fig. 3

A

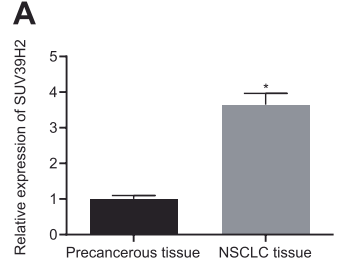

E
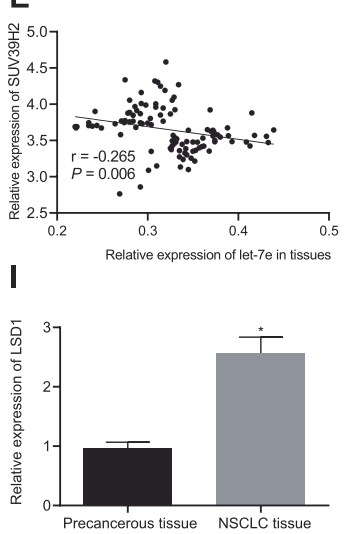

B

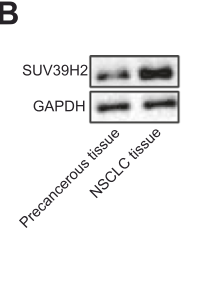

$\mathbf{F}$

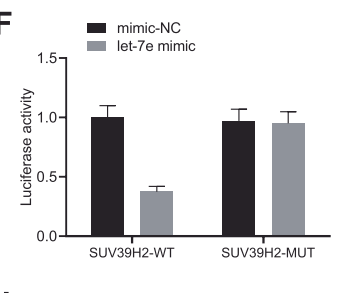

J

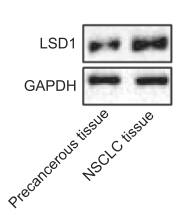

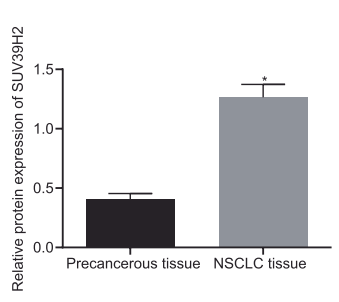

$\mathbf{G}=$ mimic.-Nc
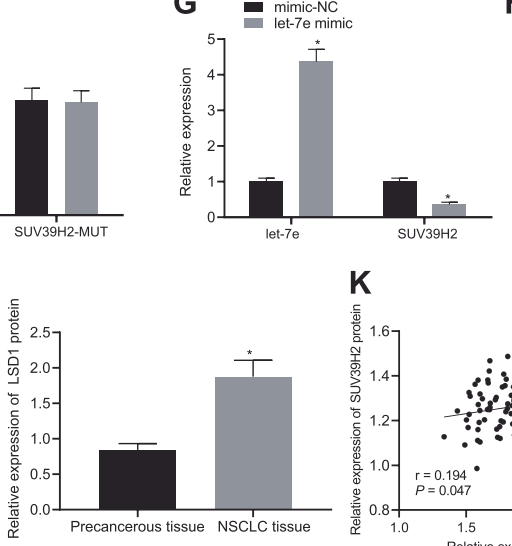

C
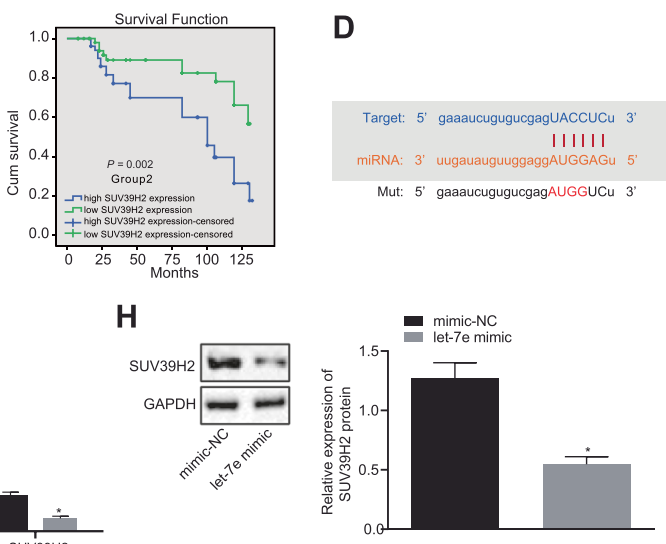

L

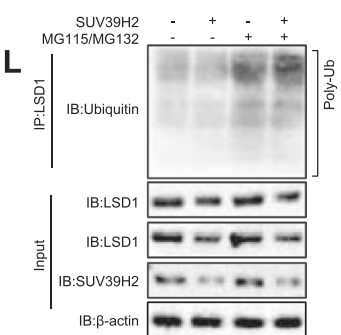

Fig. 4 


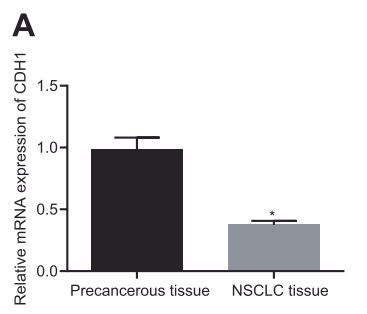

B

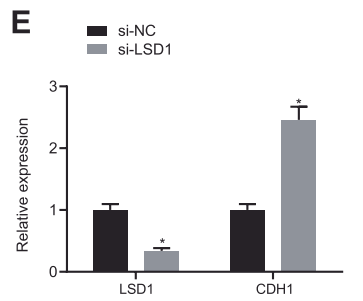

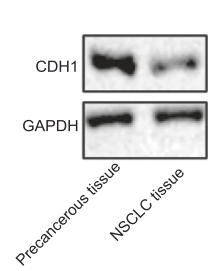

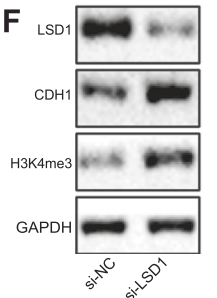

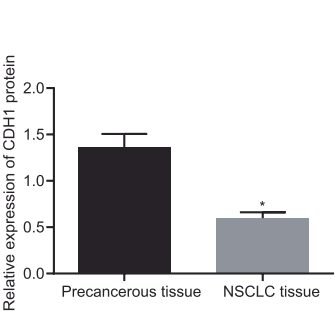

C
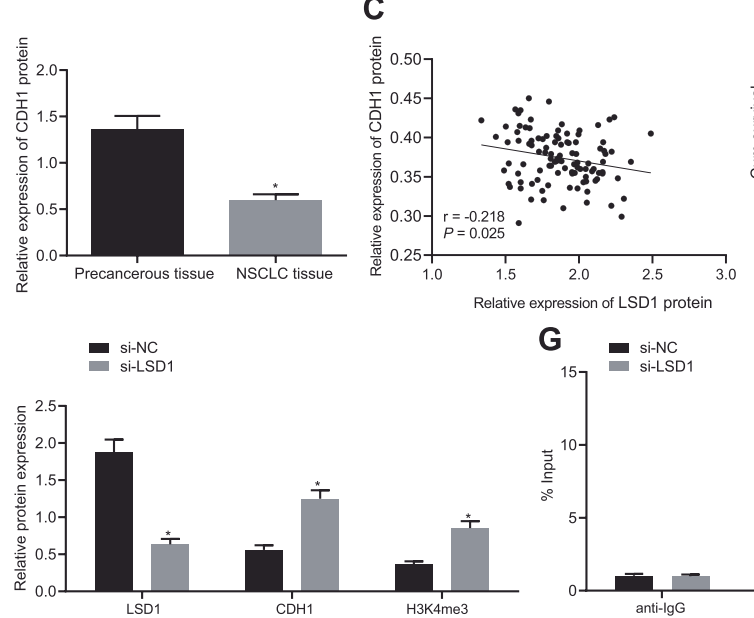

D

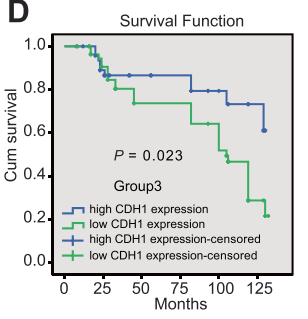

1073



Fig. 5 